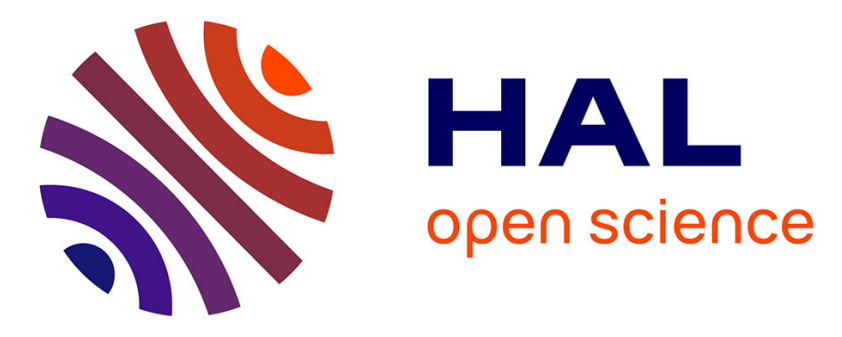

\title{
Digital Concrete: A Multi-scale Approach for the Concrete Behavior
}

Ghassan Mounajed, Frédéric Grondin, Hélène Dumontet, Abdelwahed Ben Hamida

\section{- To cite this version:}

Ghassan Mounajed, Frédéric Grondin, Hélène Dumontet, Abdelwahed Ben Hamida. Digital Concrete: A Multi-scale Approach for the Concrete Behavior. Journal of Computational Methods in Sciences and Engineering, 2006, 6 (5-6), pp.325-337. hal-01006747

\section{HAL Id: hal-01006747 \\ https://hal.science/hal-01006747}

Submitted on 3 Feb 2018

HAL is a multi-disciplinary open access archive for the deposit and dissemination of scientific research documents, whether they are published or not. The documents may come from teaching and research institutions in France or abroad, or from public or private research centers.
L'archive ouverte pluridisciplinaire HAL, est destinée au dépôt et à la diffusion de documents scientifiques de niveau recherche, publiés ou non, émanant des établissements d'enseignement et de recherche français ou étrangers, des laboratoires publics ou privés. 


\title{
Digital Concrete: A Multi-scale Approach for the Concrete Behavior
}

\author{
Ghassan Mounajed ${ }^{1,2}$ \\ Frédéric Grondin ${ }^{3}$ \\ Hélène Dumontet ${ }^{4}$ \\ Abdelwahed Ben Hamida ${ }^{5}$ \\ ${ }^{1,3}$ Centre Scientifique et Technique du Bâtiment, Division MOCAD, 84 av. Jean Jaurès, 77421 \\ Champs-sur-Marne Cedex 2, France \\ ${ }^{3,4,5}$ Laboratoire de Modélisation, Matériaux et Structures, CNRS UMR 7143, Université Paris 6, 4 place \\ Jussieu, 75252 Paris Cedex 05, France
}

\begin{abstract}
This article presents a Numerical method of homogenization in thermo-hydro-mechanic for materials based on the choice of a representative volume in which heterogeneities are generated in random process., The numerical model is used to predict elastic behaviour as well as thermal damage behaviour and the concrete permeability. This numerical model is developed and implemented in the general finite element code 'SYMPHONIE'. The Digital concrete model is used then to the calculation of the High Strength homogenized concrete behaviour. Obtained results appear in good agreement with experimental measures and show the capacity of the model to take in account the size distribution of aggregates and pores of concrete. Furthermore, this method allows through the process of localisation to estimate the local fields and to predict possible damages of the material.
\end{abstract}

Keywords: Stochastic Homogenization, Digital Concrete, Thermo-Hydro-Mechanical behaviour, Localization.

\section{Introduction}

In this study, we suggest to simulate the cement-based materials behaviour subjected to thermal, hydrous and mechanical loads using multi-scales approaches. Multi-scales techniques allow characterizing, from the knowledge of the microstructure, the heterogeneous material behaviour by substituting it an equivalent homogeneous material. That makes then possible a calculation for a complex structure. Also the interest of

\footnotetext{
${ }^{1}$ mounajed@cstb.fr

${ }^{2}$ Corresponding author

${ }^{3}$ frederic.grondin@cstb.fr

${ }^{4}$ Helene.Dumontet@iupgc.u-cergy.fr

${ }^{5}$ hamida@ccr.jussieu.fr
} 
these approaches lies in the fact that it is then possible to reach the local fields and so, to be able to predict and to follow a damage within the microstructure.

We can find a synthesis of the various proposed homogenization models these last years in J. Aboudi [1] or in M. Bornert \& al. [2]. These differences of models concern manly the choice of the Representative Elementary Volume (REV) of the material and the way with which the load is applied. Thus, simplified approaches adopt a REV with simple geometries, and representing only one heterogeneity, to give explicitly the equivalent behaviour [1,2]. While the homogenization principle of the periodic media adopts a periodic schema to represent the heterogeneities distribution in the material. These approaches consider a distribution of one heterogeneity in a simplified REV with a basic period [3], requiring, in most of cases, a numerical resolution. Others numerical approaches have been proposed. They are based on a more realistic representation of the REV by describing the microstructure with a random generation of the heterogeneities size distribution [4]. These techniques have been applied to porous medias, either by a digital-image-based by Bentz \& al. [4, 5], or by a finite element method presented by Breunesse [6].

In this article, we propose a numerical method of homogenization to analyse the thermo-hydro-mechanical behaviour of the cement-based materials. The originality of the method bases on the exploitation of the Digital Concrete model (" Béton Numérique ") [7] developed in the general Finite Element (F.E.) code 'SYMPHONIE' [8]. This model allows the generation of a rich and more realistic REV by considering the heterogeneous microstructure as a multi-phases material. This model takes in account the aggregate and pore size distributions. These heterogeneities are generated in a random way inside the REV which is discretized by the finite element method.

In this article, we present first the numerical aspects concerning the REV grid generation. After, we remind the method of homogenization in the case of a linear thermo-hydro-mechanical problem. The first application of the model concerns the homogenization of the thermal-elastic behaviour of a High Strength Concrete (HSC). Then the obtained results are compared to experimental one in order to validate the model. Finally, a parametric study of the model is presented as well as a micromechanical analysis. The recent development concerns now the homogenization of the permeability of thermally damaged concrete.

\section{Presentation of the Digital Concrete model}

\subsection{Multi-scales representation of the concrete}

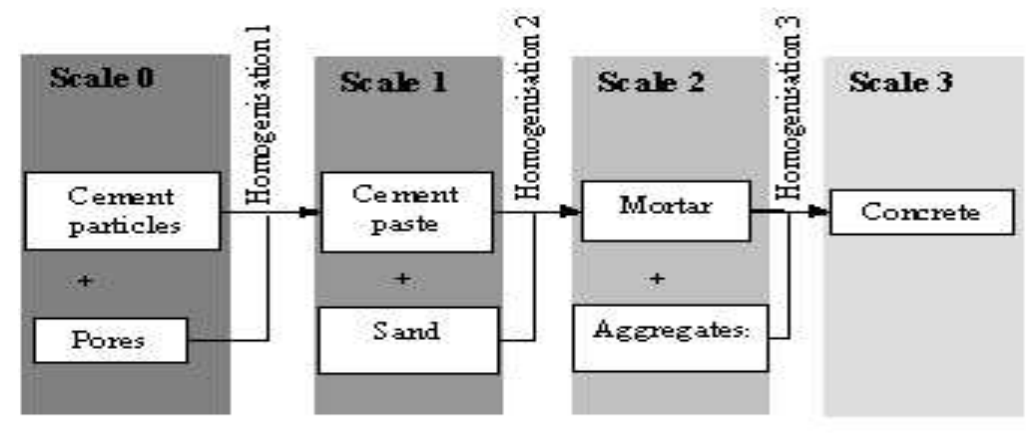

Figure 1: Different scales for the homogenization of cement-based materials. 
In this method, we consider several scales of modelling, ranging from the cement paste to the concrete material. Thus, the concrete is considered as a combination of three heterogynous materials: cement paste, mortar, and concrete. Each material is considered on its specific scale, and homogenisation is needed on each scale to go to the following upper one. Figure 1 shows the basis of this approach.

\subsection{Multi-phase approaches}

The local approach is based on the random 'Digital Concrete' model developed by Mounajed [7]. The random character is due to the concrete heterogeneously led by the random aggregate size distribution, and the random pore size distribution in the cement paste. Aggregates and pores have some characteristics different of the solid cement matrix. The proposed approach allows considering the Digital Concrete material as a multi-phases material with successions of $\mathrm{n}$ materials phases distributed spatially in a random way (Figure 2). So, in a first time, we could adopt the following phases to represent the concrete:

$$
\text { DigitalConcrete }=\sum_{i}^{\text {Nbphases }} \text { Phase }_{i} \times \text { Volume }_{i}
$$

1st phase: solid skeleton of the cement matrix $P 1$

2nd phase: a random pores size distribution with the possibility to decompose this phase in several subphases to represent various volumes and natures for pores $P 2, P 3 \ldots P x$

3rd phase a random spatial aggregates size distribution with the possibility to decompose this phase in a several sub-phases to take in account various sizes and kinds for aggregates $P x+1, \ldots, P n$

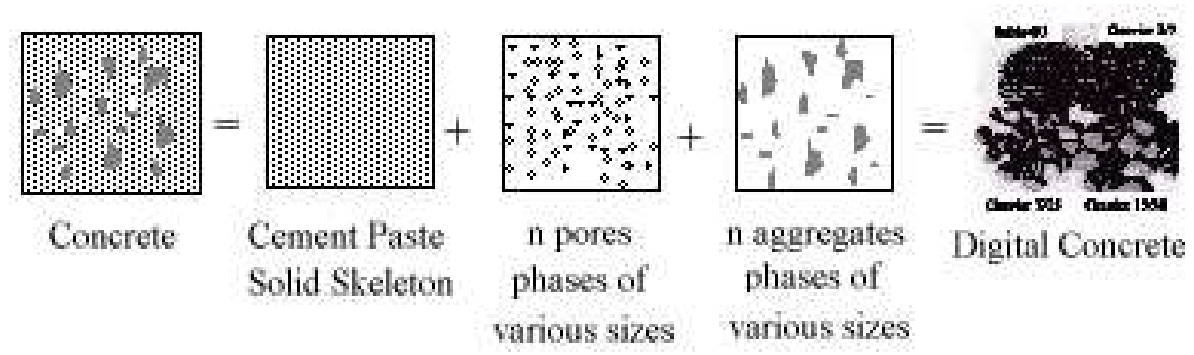

Figure 2: Presentation of various constituents distributed in a concrete.

The simulation of the concrete is approached by considering this heterogeneous mixture as a multi-phase media (pores + cement paste $+\mathrm{n}$ aggregates phases). So, the influence of each phase could be analyzed on the structural answer.

\subsection{Phase characterisation}

In this model, each phase is characterized by a set of physical and geometrical parameters as:

The phase volume percentage with regard to the total volume,

The unit size of the phase constituent (the aggregate diameter), 
The mechanical and physical characteristics of each phase: for example the Young's modulus and the Poisson's coefficient, the thermal expansion coefficient, the permeability, the conductivity, as well as the damage evolution law in tensile and in compression.

\subsection{The numerical Finite element approach}

The originality of the approach lies in the way of integrating it in a non-linear analysis by a finite element method. A specific algorithm has been developed to make a spatial and random distribution of these elementary volumes on the basis of a given F.E. mesh. The model can consider in one simulation both homogeneous and heterogeneous materials. For the material declared as a "Digital Concrete", basic properties will affect all the elements concerned with this material. The properties of the various aggregates and pores phases (unit volume, percentage, material characteristics) must be also supplied.

The proposed method consists in allocating characteristics of the initial matrix to all concerned elements. Then, all the calculation steps for the various phases generation are going to be linked by a specific algorithm. Originally, the characteristics of the basic phase of mortar will affect all elements of the mesh. At the end of the random phases generation, only the elements not affected by aggregates or pore will preserve their initial properties, all other elements will have the proprieties of the concerned generated phase.

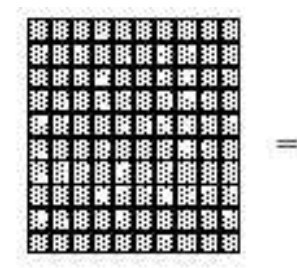

Mortar characteristics

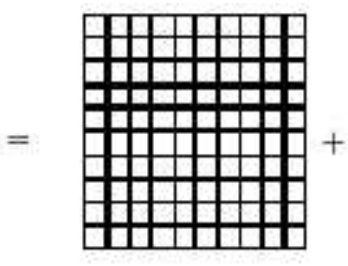

Meshing

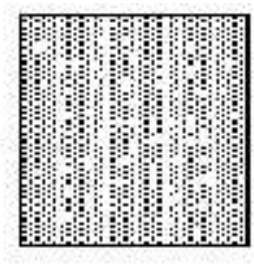

1st aggregate phase

for all elements

Figure 3: The description of the aggregates phases generation from the mortar matrix.

The digital concrete generation method have been developed and integrated in 'Symphonie' in twodimensions $(2 D)$ and in three-dimensions $(3 D)$. Algorithm details are described by Mounajed [7]. This method allows taking into account:

1. The random aspect of the phases distributions (two successive simulations lead in various distributions),

2. The multi-phase aspect (the consideration in a simultaneous way of a several phases of various sizes and natures: pores, aggregates, etc),

3. An optimized algorithm to test, according to a criterion, the random position validity of candidates aggregates and to avoid the phase interpenetration while guaranteeing the phases percentage according to the real aggregate size distribution,

4. The consideration of a transition zone between a phase and the matrix to deal with interface laws,

5. Multiple application areas: linear, non-linear, thermal, hydrous, thermo-hydro-mechanical. 


\subsection{Preliminaries calculus}

The inclusions generation requires a calculus of their number from their total volume of all elements $(V T E)$. The inclusions number of the phase $i$ will be calculated in the following order:

$$
V T E=\sum_{i}^{\text {nbelements }} V_{i}
$$

The geometric shape of the inclusion is considered as circles in $2 D$ or spheres in $3 D$ analysis. The unit volume of an inclusion of type $i$ is calculated in two-dimensions or in three-dimensions as follow:

$$
\begin{array}{cc}
V U_{-} G_{i}=\pi\left(D_{i}^{4} / 4\right) & \text { in } 2 D \\
V U_{-} G_{i}=4 / 3 \pi\left(D_{i} / 2\right)^{3} & \text { in } 3 D
\end{array}
$$

So the inclusion number of the phase $i$ is equal to:

$$
N b_{-} G_{i}=\frac{V T E}{V U_{-} G_{i}}
$$

\subsection{The inclusions random generation}

The distribution algorithm generates randomly candidate positions of the inclusions gravity centres in the area defined by the REV. Then, some tests are made to valid these positions. A first test consists to verify if this position concern an element of Digital Concrete type. We calculate the distance between the element gravity centre and that of the inclusion. If this distance is higher than the element average size, this element will have the properties of the inclusion (Figure 4).

A second test verifies that two inclusions do not overlap. The distance between an existing inclusion gravity centre, of radius $R 1$, and a candidate inclusion, of radius $R 2$, has to be higher to a value $d_{\min }$ defined as: A second test verifies that two inclusions do not overlap. The distance between an existing inclusion gravity centre, of radius $R 1$, and a candidate inclusion, of radius $R 2$, has to be higher to a value dmin defined as:

$$
d_{\text {min }}=\left(\frac{R_{1}+R_{2}}{2}\right)
$$

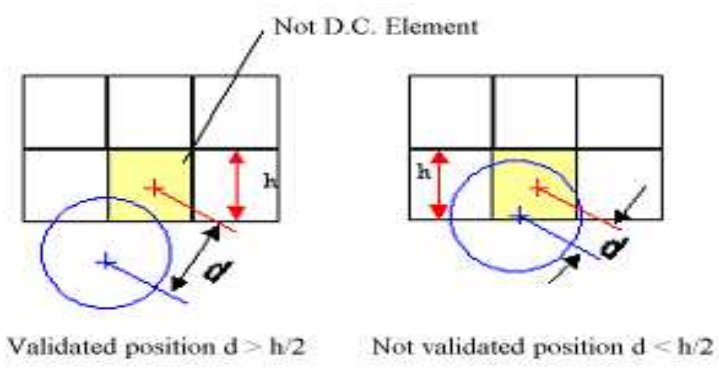

Figure 4: The position validity test of an element of Digital Concrete type. 


\subsection{Affectation of characteristics to elements}

After the model has validated the inclusions position, they are affected by characteristics materials defined by the user. Before the inclusions generation, all the elements were characterized by the material parameters of the matrix (the mortar in the HSC case). Then the model tests if the position of an element gravity centre is in an inclusion influence radius. That is if the distance between an element gravity centre and that of the inclusion is lower than this inclusion radius. In that case the considered element is affected by the inclusion material proprieties.

\subsection{The consideration of a transition phase (interface law)}

The concrete quality can not be simply deducted from a simple phase pile. Indeed, the adhesion quality between aggregates and the cement paste constitutes a determining parameter for the final mixture quality. This parameter represents in a global way an important set of hidden parameters relevant of chemical reactions and the material formulation. As such we consider in the model the adhesion law through a definition of an interfacial transition zone (ITZ) around every solid inclusion. It is defined by a band surrounding the solid inclusion with a width defined as a percentage of a given aggregate diameter. This zone possesses these own mechanical characteristics (modulus, rigidity, etc.). The following figure (Figure 5) schematizes the transition zone concept.
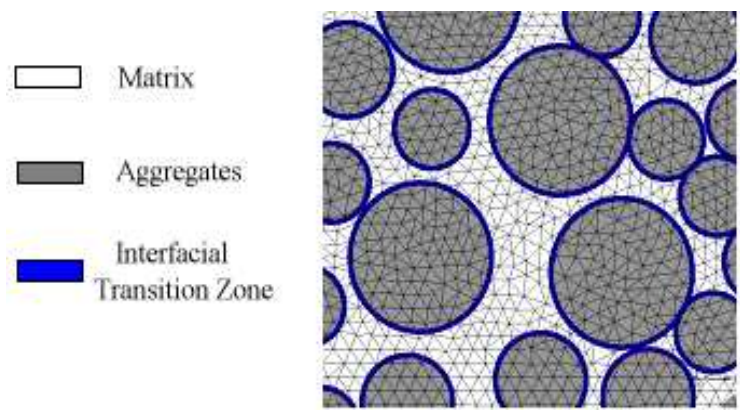

Figure 5: The definition of the ITZ between an aggregate and the cement paste.

The following figure (Figure 6) shows a random generation of a Digital Concrete in $3 D$.
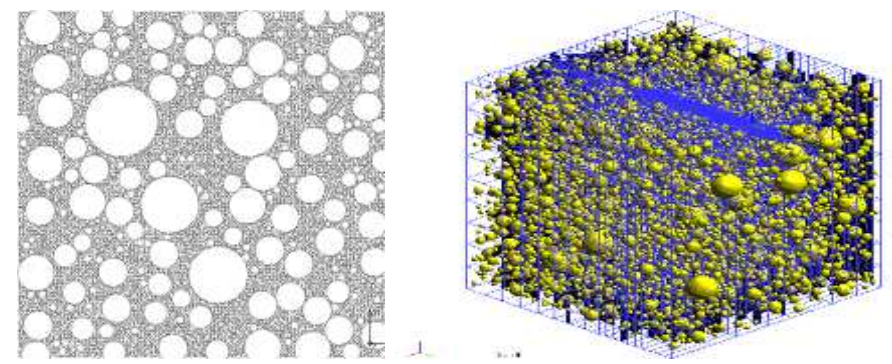

Figure 6: A digital example of the aggregate size distribution of a concrete generated by the Digital Concrete model. 


\section{Homogenization reminders in the thermo-hydro-mechanical behaviour}

The homogenization principle defines the equivalent homogeneous behaviours for heterogeneous materials. We define relationships between the local fields averages, obtained by the resolution of the cellular problems put on a REV. In this section we suggest formulating these relationships for thermo-hydro-mechanical problems.

\subsection{The coupled thermo-mechanical behaviour}

Let us consider a representative elementary volume, $V$, of a heterogeneous media. The various phase behaviours are linearly isotropic thermal-elastic. On $\mathrm{V}$ the following cellular problem is composed:

$$
\begin{aligned}
\operatorname{div}(\boldsymbol{\sigma}) & =0 & & \boldsymbol{y} \in V \\
\boldsymbol{\sigma}(\boldsymbol{y}) & =\boldsymbol{C}(\boldsymbol{y}):(\boldsymbol{\epsilon}(\boldsymbol{y})-\alpha(\boldsymbol{y}) \cdot \Delta \theta . \boldsymbol{I}) & & \boldsymbol{y} \in V \\
\boldsymbol{\epsilon}(\boldsymbol{y}) & =\frac{1}{2}\left(\nabla(\boldsymbol{u})+{ }^{t} \nabla(\boldsymbol{u})\right) & & \boldsymbol{y} \in V \\
\boldsymbol{u}(\boldsymbol{y}) & =\boldsymbol{E} \cdot \boldsymbol{y} & & \boldsymbol{y} \in \partial V
\end{aligned}
$$

$\boldsymbol{u}(\boldsymbol{y}), \boldsymbol{\epsilon}(\boldsymbol{y})$ and $\boldsymbol{\sigma}(\boldsymbol{y})$ describe displacements, microscopic strain fields and microscopic stress fields. $\boldsymbol{C}(\boldsymbol{y})$ is the rigidity tensor and $\alpha(\boldsymbol{y})$ is the coupling coefficient or the thermal expansive coefficient of various phases. $\boldsymbol{E}$ is the symmetric macroscopic strain tensor and $\Delta \theta$ is an imposed temperature rate.

The material equivalent homogeneous behaviour is given by the following homogenized behaviour law [9]:

$$
\boldsymbol{\Sigma}=\langle\boldsymbol{\sigma}\rangle_{V}=\boldsymbol{C}^{\text {hom }}:\left(\boldsymbol{E}-\boldsymbol{\alpha}^{\text {hom }} . \Delta \theta\right)
$$

The macroscopic strain field $\boldsymbol{\Sigma}$ is so defined by the imposed macroscopic strain field $\boldsymbol{E}$ and the temperature rate $\Delta \theta$. The notation $\langle f\rangle$ describes the field $f$ average on the REV $V$. We adopt the macroscopic strain field as the microscopic strain fields average $\epsilon$ which is the cellular problem solution.

In practice, the rigidity homogenized tensor $\boldsymbol{C}^{\text {hom }}$ and the thermal expansive tensor $\boldsymbol{\alpha}^{\text {hom }}$ are obtained due to the problem linearity. We resolve two problems. The one purely elastic corresponding in the macroscopic load $\boldsymbol{E} \neq 0$ and $\Delta \theta=0$. The second problem corresponding in the macroscopic load $\boldsymbol{E}=0$ and $\Delta \theta \neq 0$.

\subsection{The hydraulic behaviour}

Several approaches have been proposed to calculate the equivalent permeability tensor for porous media. We can quote explicit resolution methods [10], or numerical methods basing on the percolation theory [11], or on the Lattice-Boltzmann's theory [12]. A homogenization method, based on the finite difference method [13], is exploited afterward. We shall apply it to the Digital Concrete model, using the finite element method.

For multi-scales approaches, the hydraulic equivalent behaviour is obtained after the following cellular problem resolution:

$$
\begin{array}{rlrl}
\operatorname{div}(\boldsymbol{k} . \boldsymbol{g r a d} h) & =0 & & \text { in } V \\
\boldsymbol{v} & =-\boldsymbol{k} \cdot \boldsymbol{g r a d} h & & \\
h(\boldsymbol{y}) & =\boldsymbol{G} \cdot \boldsymbol{y} & \boldsymbol{y} \text { on } \partial V
\end{array}
$$

(10) is the diffusivity equation, and (11) is the Darcy's law. $\boldsymbol{v}$ describes the fluid flow; $\boldsymbol{k}$ is the permeability of each phase, defined by $\boldsymbol{k}=(\rho g / \mu) \cdot \boldsymbol{k}_{i}$ with $\boldsymbol{k}_{i}$ the intrinsic permeability which depends only on the 
porous media geometry, and not on fluid properties. $h=p / \rho g+z$ is the hydrous load, with $p$ the fluid pressure, $\rho$ the fluid volume density, $g$ the gravity acceleration associated to the position $z$ with regard to the ground. $G$ is the load gradient imposed answering to the boundary conditions (12) of permeameter type.

The equivalent homogeneous permeability tensor is then given by the following relationship between average fields [14]:

$$
\boldsymbol{V}=\langle\boldsymbol{v}\rangle_{V}=-\boldsymbol{K}_{b} \cdot \boldsymbol{G}
$$

We show that the pressure gradient of the macroscopic load, $\boldsymbol{G}$, is the microscopic pressure gradient average on the REV of the load $h$ according to the tensor formula proposed by Rubin and Gomez-Hernandez [13].

\section{Application to the concrete behaviour}

Multi-scales approaches, described first, coupled with the Digital Concrete model is applied after. At first, a two-dimensional REV was retained to characterize the mortar behaviour of which phases are the cement paste, pores and sand grains (Figure 7). Then, a second REV will be generated at the HSC scale of which phases are the mortar and aggregates.

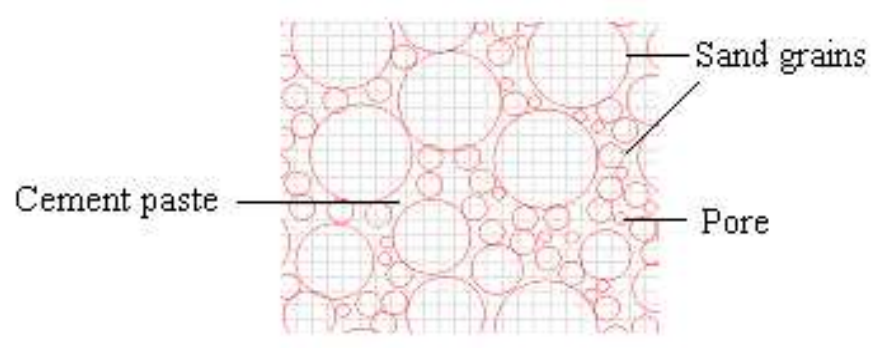

Figure 7: Description of the constituents of the mortar Representative Elementary Volume.

\subsection{The choice of geometrical parameters for the REV mesh}

Various digital tests were made to make sure of the calculation stability toward the REV size of length $L$ and the heterogeneities maximal diameter $D_{\max }$. Calculations concerned the homogenized Young's modulus $(E)$ in a two-dimensional problem. This stability is chosen as a report $L / D_{\max }$ higher than 5 (Figure 8). Light differences observed between the $E$ values for various reports $L / D_{\max } \geq 5$ are due essentially to the random aggregate size distribution. Indeed, the model can generate various inclusions positions inside the REV for the same aggregate size distribution. Real experiments are based on various samples with various inclusions positions. And the experiments results are various. So, for various aggregate size distributions, we generate some REV and we calculate the $E$ values which form a cloud of points bounded by the values $44500 M P A$ and $45000 M P A$. The difference between the minimum value and the maximum value of $E$ is lower than of experiments differences. So, we suppose there is a stability of the Digital Concrete results for $L / D_{\max } \geq 5$.

In this experiment of the REV size choice, the report between an element size and the aggregate diameter is taken equal to 0.5 . For the homogenized permeability calculations, tests on the REV size choice correspond also to the report $\mathrm{L} / \mathrm{D}=5$. In our simulations we shall then use the same elementary volumes for permeability and thermal-elastic calculations. 


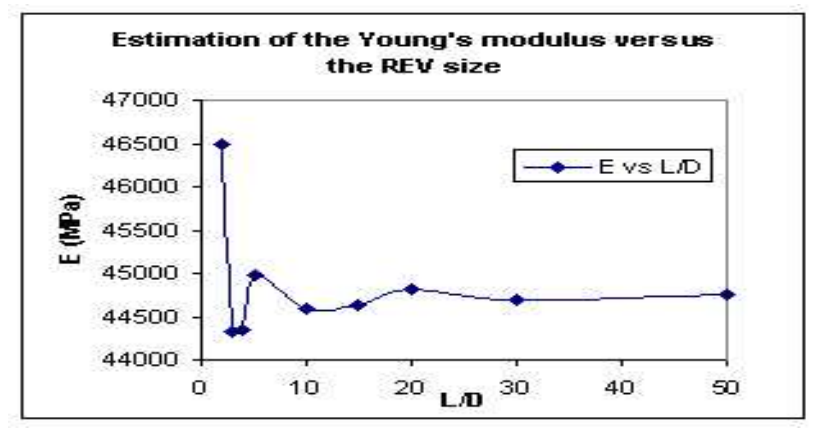

Figure 8: Determination of the REV stability according to the Young's modulus (E) versus the report $L / D_{\max }$.

Actually, computers are not enough powerful to take in account a complete aggregate size distribution of a concrete in a single calculation. Aggregates have various diameters from $70 \mathrm{~mm}$ to $20 \mathrm{~mm}$. However a study is current with the aim of verifying the results stability if for a reasonable meshing (the report between the REV size and an element size has to allow the processor calculation), we could take in account smaller inclusions (pores, very fine grains ... .) than elements. The idea is to refine the mesh only for elements where there are inclusions. We expect to define nano-mechanics of cement-based materials.

\subsection{Material description}

Thermo-mechanical properties of phases of the studied concrete, HSC $M 100 C$, were measured by Pimienta $\&$ al. [15]. They are listed in the Table 1.

\begin{tabular}{cccc}
\hline Cement paste & $E^{c}=15000 \mathrm{MPa}$ & $\nu^{c}=0.2$ & $\alpha^{c}=1.610^{-5}\left({ }^{\circ} \mathrm{C}^{-1}\right)$ \\
\hline Sand & $E^{s}=60000 \mathrm{MPa}$ & $\nu^{s}=0.2$ & $\alpha^{s}=310^{-5}\left({ }^{\circ} \mathrm{C}^{-1}\right)$ \\
\hline Aggregates & $E^{g}=60000 \mathrm{MPa}$ & $\nu^{g}=0.2$ & $\alpha^{g}=310^{-5}\left({ }^{\circ} \mathrm{C}^{-1}\right)$ \\
\hline
\end{tabular}

Table 1: The mortar and HSC aggregates thermo-mechanical characteristics.
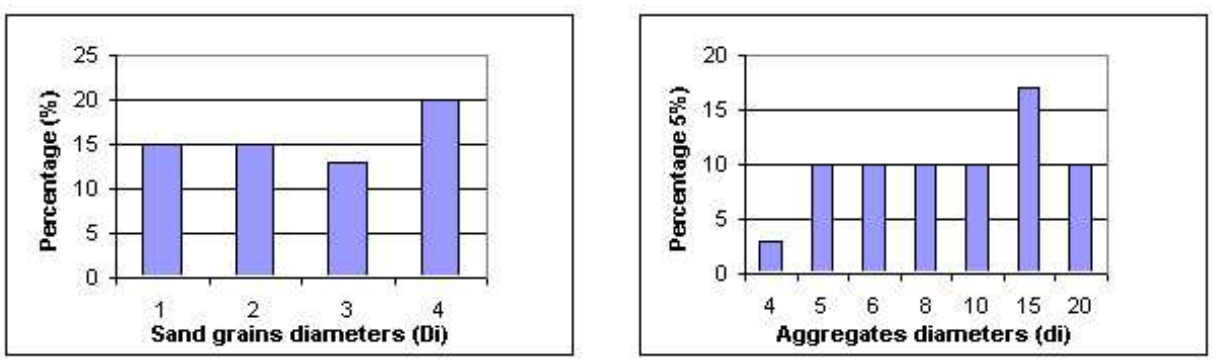

Figure 9: Left to right: Volume fractions of mortar sand grains and their sizes respectively; and Volume fractions of HSC M100C aggregates and their sizes respectively. 
The volume fraction of sand in the mortar is of $63 \%$, and the sand grains size distribution is described on Figure 9. The volume fraction of pores in the mortar is of $2 \%$. They are considered here with a constant diameter, of the order of $0.5 \mathrm{~mm}$. The volume fraction of aggregates in the HSC is of $70 \%$, and the aggregate size distribution, measured by Pimienta $\&$ al., is described on Figure 9.

\subsection{The thermo-mechanical behaviour and sensibility studies}

With the phases properties retained above, the Digital Concrete model associated to the multi-scales method, supplies the mortar equivalent behaviour then that of the concrete. The digital results obtained by twodimensional calculations, under the plane strains hypothesis, are listed in Table 2. They seem in good agreement with experimental measures [15].

\begin{tabular}{cccc}
\hline \multicolumn{3}{c}{ Mortar characteristics } \\
\hline D.C. & $E^{\text {hom }}=30187.5 \mathrm{MPa}$ & $\nu^{\text {hom }}=0.19$ & $\alpha^{\text {hom }}=8.6610^{-6}\left({ }^{\circ} \mathrm{C}^{-1}\right)$ \\
\hline Tests & $E^{\exp }=30000 \mathrm{MPa}$ & $\nu^{\text {exp }}=0.2$ & $710^{-6}<\alpha^{\exp }<1410^{-6}\left({ }^{\circ} \mathrm{C}^{-1}\right)$ \\
\hline \multicolumn{4}{c}{ HSC characteristics } \\
\hline D.C. & $E^{\text {hom }}=50610 \mathrm{MPa}$ & $\nu^{\text {hom }}=0.19$ & $\alpha^{\text {hom }}=310^{-6}\left({ }^{\circ} \mathrm{C}^{-1}\right)$ \\
\hline Tests & $E^{\exp }=50833 \mathrm{MPa}$ & $\nu^{\exp }=0.2$ & $610^{-6}<\alpha^{\exp }<1410^{-6}\left({ }^{\circ} \mathrm{C}^{-1}\right)$ \\
\hline
\end{tabular}

Table 2: Mortar and HSC homogenized thermo-mechanical characteristics obtained by the Digital Concrete model and experiments. Note: D.C. characteristics with the superscript hom are obtained by the Digital Concrete model; Tests characteristics with the superscript exp are obtained by Pimienta \& al.

The influence of aggregate and pore size distribution has then tested through various sensibility studies. We noticed that mechanical characteristics and coupling characteristics are sensitive to a porosity modification in agreement with the Dreux \& al. observations [16], and the Malier observations [17]. It can be explained by the fact that when the porosity decreases the material tends more to dilate. Indeed, the pores connexions decrease. Besides and considering the uncertainty on the cement paste mechanical properties, we studied to the sensibility study of the mortar Young's modulus according to the cement paste Young's modulus (Figure 10). The obtained evolution is similar to that observed experimentally on the other concrete types [18].

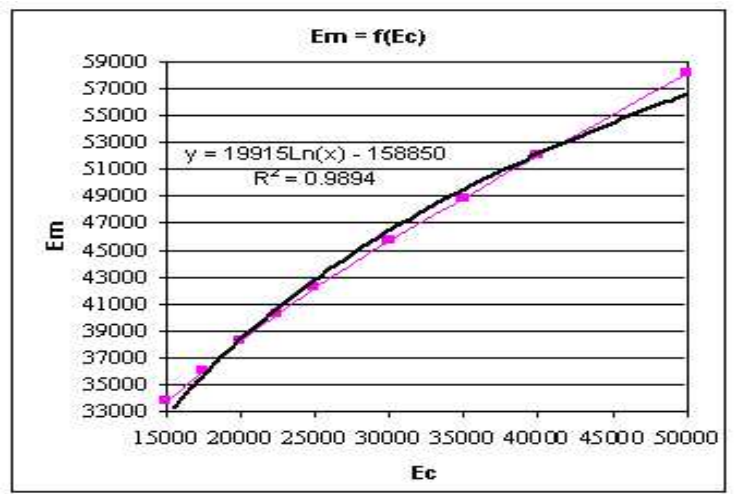

Figure 10: Influence of the cement paste Young modulus on the homogenized mortar rigidity. 


\section{Micromechanical analysis of the non-linear thermo-mechanical behaviour}

The HSC homogenized behaviour is now characterized. Multi-scale approaches allow reaching the local fields within the microstructure for a given macroscopic load. The localization principle constitutes the interest of the homogenization method proposed with regard to certain homogenization approaches simplified. These approaches do not take in account interactions between heterogeneities. In this frame a study of a thermo-mechanical coupling with damage was realized (Figure 11). The Digital Concrete model is coupled with the damage model MODEV developed by G. Mounajed and H.Q. Ung in SYMHONIE [19].

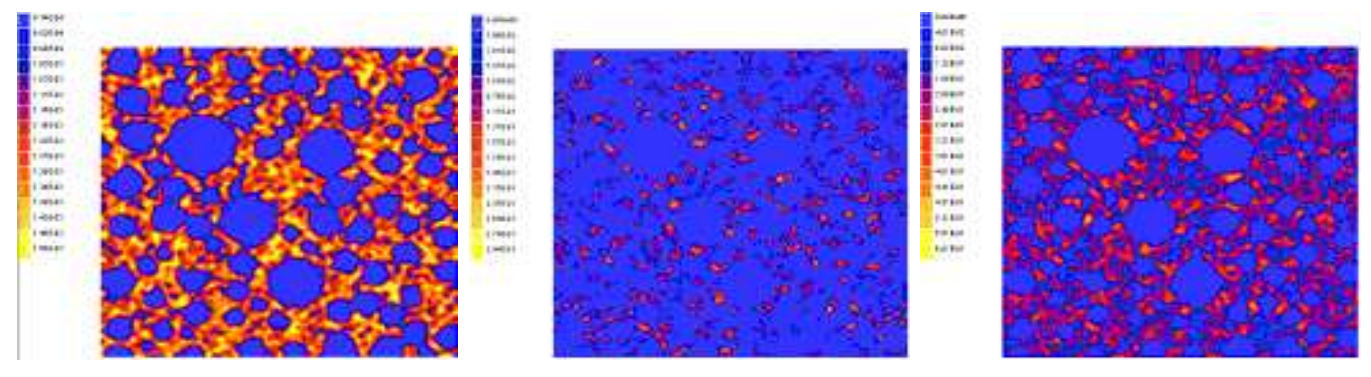

Figure 11: Simulation results for the damage calculus in a HSC under thermal loads. (From left to right: thermal strain fields, damage at $50^{\circ} \mathrm{C}$, damage at $120^{\circ} \mathrm{C}$ ).

The results of the simulation were also compared with tests of three bending points undertaken by Mounajed \& al. [20] Sullivan \& al. [21] on mortar test samples (Figure 12, 13). The simulation shows that the damage is almost steady between 120 and $250{ }^{\circ} \mathrm{C}$. This was also observed experimentally by Sullivan $\&$ al. It is necessary to note that at this level of temperature, the difference between thermal expansion coefficient of cement paste and aggregates is very small. This can explain the non-evolution of damage at this level and also confirm the local mechanical origin of the thermal damage.

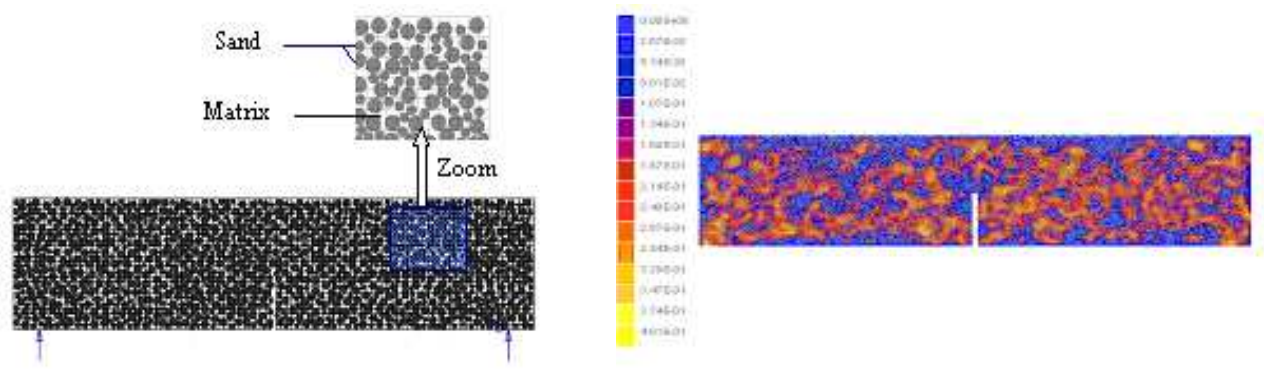

Figure 12: Generation and boundary conditions and thermal damage obtained on flexural mortar samples.

The analysis of various macroscopic behaviour models shows the incapacity of the macroscopic approach as the consideration of complex modes of the concrete degradation under the influence of the temperature [20]. Indeed, because of the strong heterogeneously of the concrete, the degradation process of this building material is governed with several mechanisms which occur in various scales to be representative of the building material complexity. Often this complex behaviour was only taken in account, for 

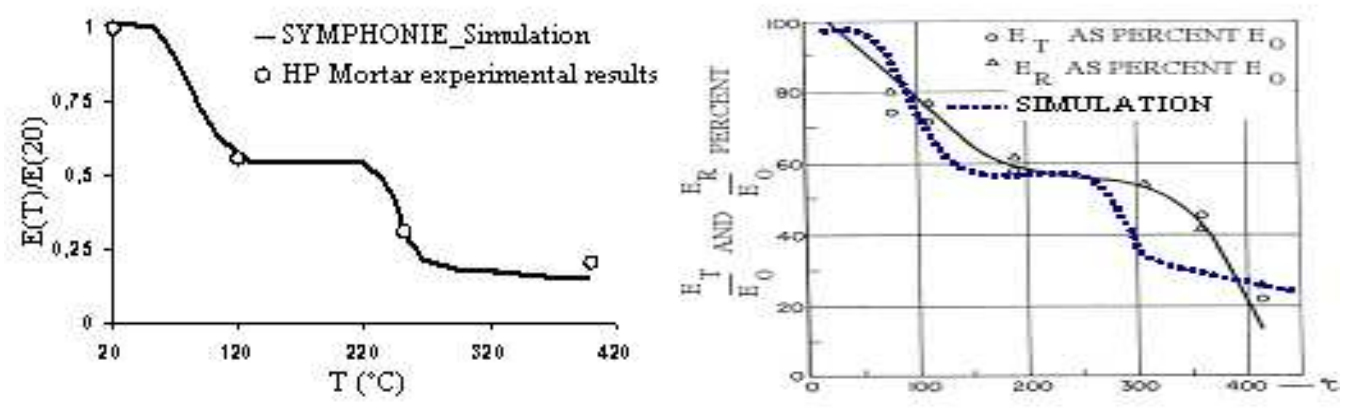

Figure 13: a and b. Comparison between experiment and simulation by digital concrete model: a) Experiment Mounajed \& al. [20], b) experiment Sullivan \& al. [21].

macroscopic behaviour models, in a semi-empirical way by reproducing in a visible way evolution according to the temperature of macroscopic characteristics [22] (Young modulus, apparent rigidity Ě). Besides the semi-empirical aspect of this approach, these models present some incapacity as for the reproduction of the concrete thermo-mechanical behaviour. By supposing the building material homogeneity, and the uniformity of the homogeneous thermal load, a concrete sample without prevented movements will dilate without stresses and so without any damage. Now experiments led on a sample subjected to such conditions show the opposite: the concrete damages under the thermal effect in moderate temperatures [20].

In the same way, the multi-scales analysis allows following the drainage evolution in the microstructure. The follow-up of this drainage at the microscopic scale can turn out of a big interest, in the damage modelling, the role which the water can play in the coupled behaviour for these materials. We can imagine this interest to simulate, for example, the microstructure degradation further to high variations in temperature (fires, freeze-thaw Ě). Actually, a study is current to follow the permeability evolution of cement-based materials according to the damage due to thermo-mechanical loads, and this for saturated and non-saturated states.

\section{Conclusions}

In this work, we developed a simulation tool, the Digital Concrete, integrated into the general F.E. code SYMPHONIE of the CSTB. It allows characterizing the concrete homogenized behaviour under a thermomechanical load by a multi-scales approach. We take in account random heterogeneities size distributions at the mortar scale and at the concrete scale. The obtained simulations results confront in a completely encouraging way with experimental results. Furthermore, this method allows reaching the strain fields and the stress fields which reign in the microstructure. A multitude of sensibility analyses of the equivalent behaviour, also of distribution of the local fields, can be begun. The Digital Concrete allows then testing several types of cement-based materials under mechanical and $\backslash$ or thermal load. For non-linear thermomechanical problems, the damage evolution is observed with a micromechanical analysis. Recent studies are going to allow determining the equivalent permeability of the HSC, from the permeability of material constituents. At a smaller scale, the determination of the permeability of the cement paste requires knowledge of the hydration of this one, and consequently the capillary network fraction in the cement paste $[23,24]$. 
The use of localization tools set up in the Digital Concrete model associated to the non-linear thermo-hydromechanical model developed in the code SYMPHONIE [25, 26, 27], will allow simulating various damage mechanisms introduced in the microstructure [28].

\section{Acknowledgements}

FG thanks H. Boussa, A. Menou and H. Ung Quoc for their participation on the thermo-mechanical coupling study with the damage model MODEV.

\section{References}

[1] J. Aboudi, 'Mechanics of Composite Materials: A unified micromechanical approach', Elsevier Science Publishers B. V., Amsterdam, 1991.

[2] M. Bornert, T. Bretheau, P. Gilormini, 'Homogénéisation en mécanique des matériaux. Tome 1', Hermès Sciences Publications, Paris, 2001.

[3] F. Devries, H. Dumontet, G. Duvaut, F. Lene, 'Homogenization and Damage for Composites Materials', International Journal of Numerical Methods in Engineering, volume 27, 285 - 298, 1989.

[4] D.P. Bentz, E.J. Garboczi, N.S. Martys, 'Application of Digital-Image-Based Models to Microstructure, Transport Properties, and Degradation of Cement-Based Materials', Modelling of Microstructure and Its Potential for Studying Transport Properties and Durability, Kluwer Academic Publishers, H. Jennings \& al. Editors, 167 - 185, 1996.

[5] D.P. Bentz, G.P. Forney, 'User's guide to the NIST Virtual cement and concrete testing laboratory. Version 1.0', NISTIR 6583, 2000.

[6] A. Breunese, 'Tensile properties of concrete during fire', Master's thesis of Delft University of Technology, 2001.

[7] G. Mounajed, 'Exploitation du nouveau modèle Béton Numérique dans Symphonie : Concept, homogénéisation du comportement thermomécanique des BHP et simulation de l'endommagement thermique', Cahiers du CSTB, $n^{\circ} 3421$, Sept. 2002.

[8] G. Mounajed, 'Code EF SYMPHONIE. SYMPHONIE, Code de calcul général aux éléments finis', CSTB report, France, 1991.

[9] G. Frankfort, 'Homogeneization and thermoelasticity', Journal of Mathematics Analysis, SIAM, volume 14, $696-708,1983$.

[10] P. Renard, 'Modélisation des écoulements en milieux poreux hétérogènes. Calcul des perméabilités équivalentes', Mémoire des Sciences de la Terre de l'Ecole des Mines de Paris, 1997.

[11] E.J. Garboczi, D.P. Bentz, 'Percolation aspects of cement paste and concrete - properties and durability', American Concrete Institute Spring Convention, march 14-19, Chicago, IL, 147 - 164, 1999.

[12] Y. Kheem, 'Computational rock physics: transport properties in porous media and applications', Ph.D of Stanford University, 2003. 
[13] J.J Gomez-Hernandez, 'A stochastic approach to the simulation of block conductivity fields conditioned upon data measured at a smaller scale', Ph.D of Stanford University, 1991.

[14] J.J Gomez-Hernandez, A.G. Journel, 'Stochastic characterization of grid-block permeabilities: form point values to block tensors', 2nd European Conference on the Mathematics of Oil Recovery, D. Guérillot, O. Guillon and Editions Technip, Paris, 83 - 90, 1990.

[15] P. Pimienta, A. Le Duff, 'Propriétés des BHP à hautes températures', Projet BHP 2000, Juillet 1996.

[16] G. Dreux, J. Festa, ’Nouveau guide du béton', Eyrolles, Paris, 1995.

[17] Y. Malier, 'Les bétons à hautes performances : caractérisation, durabilité, applications', Presses de l'Ecole Nationale des Ponts et Chaussées, Paris, 1992.

[18] G. Li, Y. Zhao, S.-S Pang, Y. Li, 'Effective Young's modulus estimation of concrete', Cement and Concrete Research, volume 29, 1455 - 1462, 1999.

[19] G. Mounajed, H. Ung Quoc, B. Mesureur, 'New tangent formulation of the concrete damage model MODEV', Werner Fuchs, Hans-Wolf Reinhardt, Rolf Eligehausen au 60ème anniversaire, Stuttgart, Germany, 2002.

[20] G. Mounajed, A. Menou, H. Boussa, A. Pineaud, S. Remond, R. Cabrillac, 'Comportement au feu des bétons. Approche multi-échelles de l'endommagement thermique et identification expérimentale des paramètres', Revue Française de Génie Civil, Edition Lavoisier, volume 7, 1299 - 1323, 2003.

[21] P.J.E. Sullivan, M.P. Poucher, 'The influence of temperature on the physical properties of concrete and mortar in the range 20 to $400^{\circ} C^{\prime}$, Temperature \& Concrete, ACI Publication SP, volume 25, $103-105,1971$.

[22] J. Stabler, G. Baker, 'On the form of free energy and specific heat in coupled thermo-elasticity with isotropic damage', International Journal of Solids and Structures, volume 37, 4691 - 4713, 2000.

[23] L. Cui, J.H Cahyadi, 'Permeability and pore structure of OPC paste', Cement and Concrete Research, volume $31,277-282,2001$.

[24] G. Consolati, F. Quasso, 'Evolution of porosity in a Portland cement paste studied through positron annihilation lifetime spectroscopy', Radiation Physics and Chemistry, Press Article, April 2003.

[25] G. Mounajed, W. Obeid, 'Thermo-hygro-mechanical coupling of saturated and non-saturated porous media, modelling by using finite element method', Workshop on modelling of deterioration in composite building components due to heat and mass transfer, BRI-Tsukuba, Japan, 1998.

[26] W. Obeid, G. Mounajed, A. Alliche, 'Experimental identification of Biot's hydro-mechanical coupling coefficient for cement mortar', Materials and Structures, RILEM, volume 35, 229 - 236, 2002.

[27] W. Obeid, G. Mounajed, A. Alliche, 'Mathematical formulation of thermo-hygro-mechanical coupling problem in non-saturated porous media', Comput. Methods Appl. Mech. Engrg., volume 190, 5105 5122, 2001.

[28] G. Mounajed, H. Ung Quoc, H. Boussa, 'Elaboration d'un nouveau modèle d'endommagement dans le code de calcul SYMPHONII-CSTB', Revue Française de Génie Civil, Edition Lavoisier, volume 7, $679-689,2002$. 